\title{
Effects of Gymnema lactiferum leaf on serum glucose and cholesterol levels of streptozotocin induced diabetic rats
}

\author{
Bandara THUSHARI ${ }^{1}$, Rokeya BEGUM ${ }^{2 *}$, Ekanayake SAGARIKA ${ }^{1}$ Ali LIAQUA T ${ }^{2}$, \\ Jansz R. ERROL ${ }^{1}$ and Balasubramanium KANDIAH ${ }^{3}$ \\ ${ }^{I}$ Department of Biochemistry, Faculty of Medical Sciences, University of Sri Jayewardenepura, Sri Lanka. \\ ${ }^{2}$ Biomedical Research Group, BIRDEM, 122 KN Islam Avenue, Dhaka, Bangladesh. \\ ${ }^{3}$ Biotech (Pvt) Ltd, Jaffna, Sri Lanka. \\ *Corresponding author, E-mail: b_rokeya@yahoo.com; Tel.: +880-2-8617130; Fax: 880-2-8611138
}

\begin{abstract}
Gymnema lactiferum var. lactiferum is distributed in Assam, Malay Peninsula, Malaysia and Sri Lanka. The leave of this plant is popular as a treatment for diabetes. However, scientific data is not available on this. The present study was designed to determine the effects of G. lactiferum leaf on glycaemic and lipidemic status in type 2 diabetic rats. Fasting blood sugar (FBS) levels of the diabetic rats reduced significantly $(\mathrm{p}=0.001)$ after 28 days of the treatment. A significant decline $(\mathrm{p}=0.015)$ was also seen in the serum total cholesterol levels. Results indicate that G. lactiferum leaf powder possesses hypoglycaemic and hypocholesterolaemic effects on type 2 diabetic rats and therefore it is postulated that it would make a good functional food for type 2 diabetic subjects.
\end{abstract}

(C) 2010 International Formulae Group. All rights reserved.

Keywords: Gymnema lactiferum var. lactiferum, Type 2 diabetic rats, hypoglycaemic, hypocholesterolaemic

\section{INTRODUCTION}

Gymnema lactiferum var. lactiferum is a green leafy vegetable which is used in salads, curries and herbal gruels. This plant closely resembles Gymnema sylvestre and both plants belong to the same family, Asclapiadaceae. G. lactiferum is distributed in Assam, Malay Peninsula, Malaysia and in Sri Lanka (Dasanayake and Fosberg, 1983). In Sinhala it is popularly known as 'Kuringnan' (The Sri Lankan Forester, 1974; Dasanayake and Fosberg, 1983). However, G. sylvestre (Sinhala - Masbedda, Muva kiri- vel or binnuga) is also known as 'Kuringnan'. The plant G. sylvestre has been proven of hypoglycaemic property (Baskaran et al., 1990). Extensive work has been carried out with $G$. sylvestre both on animals and humans. A study on the effects of a water extract of $G$. sylvestre (GS4) on insulin-dependent diabetic patients has shown a significant reduction in blood glucose, glycosylated hemoglobin and glycosylated plasma proteins (Shanmugasundarum et al., 1990). This study has further indicated that the GS4 therapy has been effective in returning the serum lipid profiles to near normal levels in insulindependent diabetic patients (Shanmugasundarum et al., 1990). There is a folkloric history among the people in Jaffna, Sri Lanka, 
of using the leaves of the plant $G$. lactiferum as a treatment for diabetes, over a long period of time. The present study was designed to analyze the effects of $G$. lactiferum leaf powder on the serum glucose and cholesterol levels of streptozotocin (STZ)-induced diabetic rats. This is the first scientific animal study which has been carried out on the leaf of G. lactiferum to evaluate its therapeutic potential on diabetes.

\section{MATERIALS AND METHODS \\ Preparation of the leaf powder}

Plants were identified at the National Herbarium, Sri Lanka. They were grown in Jaffna, Sri Lanka without using insecticides and fungicides and were supplied with organic composts. Mature leaves were dried hygienically in sunlight for 4-5 days. The dried leaves were ground and sieved to prepare the leaf powder.

\section{Experimental animals and their standard diet}

Study was carried out on male Long Evans rats (weight 150-210 g), inbred in the Research division, Bangladesh Institute for the Research and Rehabilitation of Diabetes Endocrine and Metabolic disorders (BIRDEM), Dhaka, Bangladesh. Ethical clearance was obtained from the ethical committee, BIRDEM. Around 8-10 rats were included in each experimental group.

Type 2 diabetes was induced by a single intraperitoneal injection of STZ at a dose of $90 \mathrm{mg} / \mathrm{kg} \mathrm{B.W.} / 10 \mathrm{~mL} 0.1 \mathrm{M}$ citrate buffer ( $\mathrm{pH} 4.5$ ), to $48 \mathrm{~h}$ old rat pups (Bonner et al., 1981). Before the experiments (after 3 months of STZ injection), rats were tested to confirm whether they are diabetic. For this purpose their fasting blood glucose levels after $30 \mathrm{~min}$ of an oral glucose load $(2.5 \mathrm{~g} / \mathrm{kg}$ B.W.) were determined. Rats with fasting blood sugar value ranging from 7.5-10 $\mathrm{mmol} / \mathrm{L}$ and value of $15 \mathrm{mmol} / \mathrm{L}$ or above after $30 \mathrm{~min}$ were used in the study.

Standard rat pallet contained wheat (40\%), wheat bran $(20 \%)$, rice polishings $(5 \%)$, fish meal $(10 \%)$, oil cake $(10 \%)$, gram (3.9\%), pulses $(3.9 \%)$, milk $(3.8 \%)$, soya bean oil $(1.5 \%)$, molasses $(0.95 \%)$ and salt
(0.95\%). Embavit GS (vitamin mixture) $250 \mathrm{~g}$ was added per $100 \mathrm{~kg}$ of rat food.

\section{Acute effect of G. lactiferum leaf on blood glucose levels}

Rats were fasted for $12 \mathrm{~h}$ with free access to water. Fasting blood samples were taken from the tip of tail. G. lactiferum leaf powder $(1.25 \mathrm{~g} / \mathrm{kg} \mathrm{B.W.)}$ was administered to diabetic rats orally, $30 \mathrm{~min}$ before a glucose load (2.5 g/kg B.W.), using a syringe with a metallic tube that was smooth and curved at the end which led the feed direct to the stomach. The control rats were fed with an equal volume of deionized water. A Glibenclamide group (positive control) was fed with a dose of $5 \mathrm{mg} / \mathrm{kg} \mathrm{B.W./day.} \mathrm{Blood}$ samples drawn after $60 \mathrm{~min}$ and $105 \mathrm{~min}$ were analyzed for glucose.

\section{Effects on the chronic consumption of $G$. lactiferum leaf}

Diabetic rats were divided into three groups ( $\mathrm{n}=8$ in each group) and they were treated as follows.

1. Vehicle group - given water

2. Standard drug treated group Glibenclamide was administered at a dose of $5 \mathrm{mg} / \mathrm{kg} \mathrm{B.W./day} \mathrm{for} \mathrm{four}$ weeks.

3. Test group - treated with $G$. lactiferum leaf powder at a dose of $1.25 \mathrm{~g} / \mathrm{kg} \mathrm{B}$.W. for four weeks.

Body weights of the rats were measured each week. Blood was drawn on day zero, 7, 14 and 21 by amputation of the tail tip. On the $28^{\text {th }}$ day the animals were sacrificed and blood samples were collected, centrifuged at 4000 $\mathrm{rpm}$ for $10 \mathrm{~min}$ and re-centrifuged at 3000 rpm for $5 \mathrm{~min}$. The level of serum glucose was determined (by GOD-PAP kit) using micro plate reader (Kunst et al., 1984), from the $7^{\text {th }}, 14^{\text {th }}$ and $21^{\text {st }}$ day samples. Total cholesterol (Allain et al., 1974), triglycerides (Tietz, 1990), HDL-cholesterol (Hainline et al., 1980), LDL-cholesterol (Friedewald et al., 1972), glucose (Kunst et al., 1984), insulin (Kratzsch et al., 1990), alanine transaminase (International Federation of Clinical Chemistry, 1980) and creatinine levels (Toro and Ackermann, 1975) were measured from 
serum samples of the day zero and last day. Liver glycogen contents of the rats were determined by Anthrone-sulfuric acid method (Vries, 1954) at the end of the study period.

\section{Statistical analysis}

Results are presented as mean \pm standard deviation (SD). Groups of data were compared using paired student's t-test and One-way ANOVA test as indicated with the results. Differences were considered significant at $\mathrm{p}<0.05$.

\section{RESULTS AND DISCUSSION Acute experiment}

G. lactiferum leaf powder did not produce any significant acute effect on blood glucose levels of type 2 diabetic model rats when leaf powder was given $30 \mathrm{~min}$ before an oral glucose load $(p=0.430$ at $60 \mathrm{~min}, \mathrm{p}=$ 0.117 at $105 \mathrm{~min}$ and $\mathrm{p}=0.229$ for the increment over basal value as compared by one-way ANOVA test). However, the chronic consumption of the leaf powder brought about many beneficial effects for the type 2 diabetic model rats.

\section{Chronic experiments}

The changes in the body weights of rats were not remarkably different between different treated groups during the treatment period ( $\mathrm{p}=0.865$, as compared by one-way ANOVA test). Oral administration of the $G$. lactiferum leaf powder for 28 consecutive days resulted in a gradual reduction in serum fasting glucose levels (15.5\% and $37.3 \%$ on the day 14 and 28 respectively) and on the day 28 the levels were significantly low $(\mathrm{p}=0.001)$ as shown in Table 1. Glycogen metabolism in the liver regulates the blood glucose level. The control of the synthesis and breakdown of glycogen in the liver is central to the regulation of glucose homeostasis. Liver glycogen level was estimated to determine if G. lactiferum leaf powder could increase liver glycogen content thereby exerting a hypoglycemic action. In the present study there was no significant effect $(\mathrm{p}=1.000)$ on glycogen deposition in the liver.

Unlike G. sylvestre, G. lactiferum did not affect the serum insulin levels as well.
Fasting serum insulin content did not change in Gymnema treated group ( $\mathrm{p}=0.893$ ) whereas a $26.3 \%$ increase was observed in glibenclamide treated group $(\mathrm{p}=0.612)$.

Therefore, it is evident that the hypoglycaemic effect of $G$. lactiferum is brought about by some extra pancreatic factors, which are not related to the level of serum insulin. However, any factor which can either trigger insulin activity or which can overcome insulin resistance or which can inhibit the intestinal glucose absorption may be contributory to the hypoglycaemic effect.

Dyslipidaemia is an important risk factor for atherosclerotic complications of diabetes (Laakso and Lehto, 1997). Hypercholesterolaemia and hypertriglyceridaemia have been reported to occur in STZ diabetic rats (Sharma et al., 1997). Therefore, it was considered that estimating serum cholesterol, triglycerides, HDL-cholesterol and LDL-cholesterol levels was worthwhile. Serum total cholesterol levels of the Gymnema treated group reduced significantly $(\mathrm{p}=0.015)$ with $9.01 \%$ reduction as shown in Table 2. On the other hand HDL-cholesterol level increased by $39.42 \%(\mathrm{p}=0.165)$. Serum TG level and LDL-cholesterol level reduced by $23.5 \%$ and $12.3 \%$ respectively in the Gymnema treated group. However, those reductions were not significant $(\mathrm{p}=0.465$ and $\mathrm{p}=0.189$ respectively) as shown in Table 3 . The observed hypocholesterolaemic effect may probably be due to the indirect effect of blood glucose lowering or due to any other active principle which can inhibit the cholesterol synthesis or increase cholesterol or bile salt excretion which is yet to be confirmed.

Chronic consumption of the leaf powder did not indicate any adverse effects on liver and kidneys in the type 2 diabetic rats as determined by their serum ALT and creatinine levels. Serum creatinine levels remained unchanged throughout the study period among the different groups whereas serum ALT levels reduced significantly in glibenclamide group $(p=0.014)$ while the values of other groups remained steady (Table 4 ). 
Table 1: Effect of G. lactiferum leaf powder on glycaemic status of type 2 diabetic rats.

\begin{tabular}{lccccc}
\hline \multirow{2}{*}{ Group } & \multicolumn{5}{c}{ Fasting serum glucose levels $(\mathbf{m m o l} / \mathrm{L})$, Mean \pm SD } \\
\cline { 2 - 6 } & Day 0 & Day 7 & Day 14 & Day 21 & Day 28 \\
\hline Water (n=6) & $9.03 \pm 0.68$ & $9.13 \pm 0.90$ & $8.54 \pm 1.63$ & $7.81 \pm 1.99$ & $7.79 \pm 1.82$ \\
Glibenclamide(n=6) & $9.50 \pm 1.15$ & $9.82 \pm 1.52$ & $10.30 \pm 1.15$ & $10.33 \pm 4.07$ & $7.19 \pm 1.50$ \\
G. lactiferum (n=6) & $8.95 \pm 1.36$ & $10.18 \pm 4.23$ & $7.76 \pm 3.54$ & $8.75 \pm 0.86$ & $5.56^{*} \pm 0.72$ \\
\hline
\end{tabular}

" $\mathrm{p}=0.001$ in comparison to day 0 (as determined by the paired student's t-test)

Table 2: Effect of G. lactiferum leaf powder on serum total cholesterol and HDL levels.

\begin{tabular}{llllc}
\hline \multirow{3}{*}{ Group } & \multicolumn{3}{c}{ Serum levels (mg/dL), Mean \pm SD } \\
\cline { 2 - 5 } & \multicolumn{2}{c}{ Total Cholesterol } & \multicolumn{2}{c}{ HDL } \\
\cline { 2 - 5 } & \multicolumn{1}{c}{ Day 0 } & Day 28 & Day 0 & Day 28 \\
\hline Water (n=6) & $67.00 \pm 3.58$ & $69.67 \pm 13.77$ & $29.33 \pm 3.72$ & $34.83 \pm 8.70$ \\
Glibenclamide $(\mathrm{n}=6)$ & $70.83 \pm 10.96$ & $66.00 \pm 9.90$ & $31.50 \pm 6.95$ & $32.33 \pm 7.15$ \\
G. lactiferum $(\mathrm{n}=6)$ & $76.00 \pm 7.18$ & $69.00^{*} \pm 6.07$ & $27.67 \pm 4.67$ & $36.67 \pm 10.13$ \\
\hline
\end{tabular}

" $\mathrm{p}=0.015$ in comparison to day 0 (as determined by the paired student's t-test)

Table 3: Effect of G. lactiferum leaf powder on serum LDL and TG levels.

\begin{tabular}{lcccc}
\hline \multirow{2}{*}{ Group } & \multicolumn{4}{c}{ Serum levels $(\mathbf{m g} /$ dL), Mean \pm SD } \\
\cline { 2 - 6 } & \multicolumn{3}{c}{ LDL } & \multicolumn{3}{c}{ TG } \\
\cline { 2 - 5 } & Day 0 & Day $\mathbf{2 8}$ & Day 0 & Day 28 \\
\hline Water (n=6) & $19.37 \pm 7.76$ & $19.93 \pm 7.95$ & $91.50 \pm 20.03$ & $74.67 \pm 22.32$ \\
Glibenclamide $(\mathrm{n}=6)$ & $20.23 \pm 4.77$ & $20.80 \pm 6.90$ & $95.50 \pm 26.22$ & $64.33^{*} \pm 14.94$ \\
G. lactiferum $(\mathrm{n}=6)$ & $28.17 \pm 12.91$ & $14.90 \pm 11.06$ & $100.83 \pm 21.78$ & $87.00 \pm 43.29$ \\
\hline
\end{tabular}

" $\mathrm{p}=0.018$ in comparison to day 0 (as determined by the paired student's t-test)

Table 4: Effect of G. lactiferum leaf powder on liver and kidney function.

\begin{tabular}{lcccc}
\hline \multirow{2}{*}{ Group } & \multicolumn{2}{c}{$\boldsymbol{A L T}(\mathrm{U} / \mathrm{I})$, Mean $\pm \boldsymbol{S D}$} & \multicolumn{2}{c}{ Creatinine $(\boldsymbol{m g} / \boldsymbol{d L})$, Mean $\pm \boldsymbol{S D}$} \\
\cline { 2 - 5 } & Day 0 & Day $\mathbf{2 8}$ & Day & Day 28 \\
\hline Water $(\mathrm{n}=6)$ & $90.17 \pm 19.29$ & $95.17 \pm 13.72$ & $0.64 \pm 0.06$ & $0.65 \pm 0.07$ \\
Glibenclamide $(\mathrm{n}=6)$ & $94.33 \pm 11.13$ & $80.50^{*} \pm 13.64$ & $0.64 \pm 0.06$ & $0.67 \pm 0.06$ \\
G. lactiferum $(\mathrm{n}=6)$ & $97.83 \pm 15.82$ & $101.00 \pm 21.93$ & $0.62 \pm 0.07$ & $0.67 \pm 0.08$ \\
\hline p $=0.014$ in comparison to day 0 (as determined by the paired student's t-test)
\end{tabular}

" $\mathrm{p}=0.014$ in comparison to day 0 (as determined by the paired student's $\mathrm{t}$-test)

From the data obtained it could be concluded that $G$. lactiferum leaf powder possesses hypoglycaemic and hypocholesterolaemic effects on type 2 diabetic rats and it is postulated that it would make a good functional food for type 2 diabetic subjects. These findings have been confirmed by a subsequent study carried out on type 2 diabetic patients (Bandara et al., 2009).

\section{ACKNOWLEDGEMENTS}

The financial support given by IPICS (International Programe in Chemical Sciences, Sweden) and ANRAP (Asian Network of Research on Antidiabetic Plants, Bangladesh) 
is gratefully acknowledged. Authors are grateful to the technical staff of the Research Division, Bangladesh Institute for Research and Rehabilitation in Diabetes Endocrine and Metabolic Disorders (BIRDEM), Dhaka, Bangladesh for their help.

\section{REFERENCES}

Allain CC, Poon LS, Chan CSG, Richmond W, Fu PC. 1974. Enzymatic determination of total serum cholesterol. Clinical Chemistry, 20: 470-475.

Bandara T, Rokeya B, Khan S, Ali L, Ekanayake S, Jansz ER, Balasubramanium K. 2009. Effects of Gymnema lactiferum leaf on glycemic and lipidemic status in type 2 diabetic subjects. Bangladesh J Pharmacol., 4: 92-95.

Baskaran K, Ahamath BK, Shanmugasundarum KR, Shanmugasundarum 1990. Antidiabetic effect of a leaf extract from Gymnema sylvestre in non-insulin dependent diabetes patients. Journal of Ethnopharmacology, 30: 295-305.

Bonner-Weir S, Trent DF, Honey RN, Weir GC. 1981. Responses of Neonatal Rat Islets to Streptozotocin, Limited B-cell Regeneration and Hyperglycaemia. Diabetes, 30: 64-69.

Dasanayake MD, Fosberg FR.1983. A Revised Hand Book to the Flora of Ceylon (Vol. IV). Amering Publishers Co. Pvt. Ltd: New Delhi.

Friedewald WT, Levy RI, Fedrickson DS. 1972. Estimation of the concentration of Low-density Lipoprotein Cholesterol in plasma,without use of the preparative Ultracentrifuge. Clinical Chemistry, 18: 499-502.

Hainline AJR, Cooper GR, Olansky AS. 1980. CDC Survey of High-Density Lipoprotein Cholesterol Measurement: A Report. Atlanta Lipid Standardization Programe. Center for Disease Control; 3.
International Federation of Clinical Chemistry. 1980. Scientific Committee, Journal of Clinical Chemistry and Clinical Biochemistry, 18: 521-534.

Kratzsch J, Ackermann W, Leliacker H, Berch W, Keller E. 1990. A sensitive sandwich enzyme immunoassay for measurement of insulin on microtitre plates. Experimental and Clinical Endocrinology, 95: 229-236.

Kunst A, Draeger B, Ziegenhorn J. 1984. Methods of Enzymatic Analysis (Vol. 6). Weinheim W. Germany-Deerfield Beach: Florida.

Laakso M, Lehto S. 1997. Epidemiology of macrovascular disease in diabetes. Diabetes Research, 5: 294-315.

Shanmugasundaram ER, Rajeswari G, Baskaran K, Rajesh Kumar BR, Radha Shanmugasundaram K, Kizar Ahmath B. 1990. Use of Gymnema sylvestre leaf extract in the control of blood glucose in insulin-dependent diabetes mellitus. Journal of Ethnopharmacology, 30(3): 281-94.

Sharma SR, Dwivedi SK, Swarup D. 1997. Hypoglycemic, antihyperglycemic and hypolipidemic activities of Caesalpinia bonducella. Journal of Ethnopharmacology, 58: 39-44.

The Sri Lankan Forester (The Ceylon Forester).1974, Vol. XI, No 3 and 4. Published by Sri Lanka Forest Department.

Tietz NW. 1990. Clinical guide to Laboratory Tests (2nd edn). W.B. Saunders Company: Philadelphia, USA; 554-556.

Toro G, Ackermann PG. 1975. Practical Clinical Chemistry. Little Brown and Co: Boston; 154.

Vries JV. 1954. Two methods for the determination of glycogen in liver. Biochemical Journal, 57: 410-416. 